\title{
Somatosensory Stimulation in Functional Neuroimaging: A Review
}

\author{
S.M. Golaszewski et al.* \\ ${ }^{1}$ Department of Neurology and Neuroscience Institute, \\ Paracelsus Medical University Salzburg, \\ ${ }^{2} \mathrm{Karl}$ Landsteiner Institute for Neurorehabilitation and Space Neurology Vienna \\ Austria
}

\section{Introduction}

Functional brain imaging of the somatosensory system has evolved over the past two decades and it has become an important tool in the preoperative planning in neurosurgery, in the monitoring in neurorehabilitation and for the understanding of motor recovery after brain damage for the planning and optimization of neurorehabilitation strategies.

Mapping of movement related cortical areas and areas that are related to body sensation was initially performed during neurosurgical procedures using direct cortical stimulation (Penfield, 1937). Several functional brain mapping techniques have subsequently evolved (Toga and Mazziotta, 2002). The era of functional brain imaging began in the 1980s with the implementation of the Positron Emission Tomography (PET) which provided a measure of the regional cerebral blood flow. Since the 1990s functional brain imaging is dominated by the rise of functional magnetic resonance imaging (fMRI) based on the blood oxygenation level dependant (BOLD) effect that was discovered 1990 by Ogawa et al. (Ogawa et al., 1990;Ogawa et al., 1992). Subsequently continuous evolution and progress of fMRI as well as its increasing popularity and spreading clinical use as a highly sensitive diagnostic neuroimaging instrument suitable for the assessment of a large variety of neurological and neurosurgical indications made fMRI to the leading functional neuroimaging modality. In this chapter we review somatosensory stimulation in PET and fMRI during the past decades, their advantages and disadvantages, optimal stimulation protocols as well as corresponding brain maps of different approaches of somatosensory stimulation in functional brain imaging and their clinical and neurophysilogical applications.

\section{Positron Emission Tomography}

In the 1980s, Positron Emission Tomography (PET) was used for the first time to detect focal neuronal activation within the primary somatosensory cortex of humans induced by

\footnotetext{
${ }^{*}$ M. Seidl ${ }^{1}$, M. Christova2 ${ }^{2}$ E. Gallasch ${ }^{2}$, A.B. Kunz ${ }^{1,5}$, R. Nardone ${ }^{1,3}$, E. Trinka ${ }^{1}$ and F. Gerstenbrand ${ }^{4,5}$ ${ }^{1}$ Department of Neurology and Neuroscience Institute, Paracelsus Medical University Salzburg, Austria 2Institute of Physiology, Medical University Graz, Austria

${ }^{3}$ Department of Neurology, F. Tappeiner Hospital Meran, Italy

${ }^{4}$ Department of Neurology, Medical University Innsbruck, Austria

${ }^{5} \mathrm{Karl}$ Landsteiner Institute for Neurorehabilitation and Space Neurology Vienna, Austria
} 
cutaneous vibratory stimulation with a vibration frequency of $50 \mathrm{~Hz}$ and an amplitude of 1 $\mathrm{mm}$ (Fox et al., 1987). $\mathrm{H}_{2}{ }^{15} \mathrm{O}$ labeled water was used as a blood flow tracer. The cutaneous surfaces of lips, fingers, and toes were tested. Intense and highly focal distinct responses within the primary somatosensory cortex with a medial-to-lateral homunculus were seen in each subject. The study demonstrated that eliciting regional cerebral blood flow responses within the somatosensory cortex by cutaneous vibration provides a safe, rapid, and reproducible tool for locating and assessing its functional status and for the localization of the central sulcus that is crucial in preoperative neurosurgical planning. The study has established normative values for future applications of the vibration paradigm in functional brain imaging.

In 1990, Tempel and Perlmutter compared the regional cerebral blood flow responses to vibrotactile stimulation in patients with predominantly unilateral idiopathic focal dystonia and normal subjects using $\mathrm{H}_{2}{ }^{15} \mathrm{O}$ PET (Tempel and Perlmutter, 1990). The somatosensory stimulation led to consistently localized and robust peak response in the primary sensorimotor cortex, contralateral to hand vibration in normal subjects. The sensorimotor response in dystonic patients was also consistently localized to the same area, but significantly reduced in magnitude when vibrating the affected as well as the unaffected hand. Furthermore, vibration induced a dystonic cramp in the stimulated arm and hand in some patients, but in no normal subjects. This abnormal sensorimotor response had important implications for the understanding of the pathophysiology of idiopathic dystonia. Two years later, Tempel and Perlmutter performed another significant $\mathrm{H}_{2}{ }^{15} \mathrm{O}$ PET study with vibration-induced regional cerebral blood flow responses in healthy young and elder subjects in order to investigate whether vibration-induced regional cerebral blood flow responses change with increasing age (Tempel and Perlmutter, 1992). Left and right hand vibration led to consistent responses within the contralateral primary sensorimotor cortex and the supplementary motor area with no changes in the physiologically aging brain.

In the same year, Seitz and Roland were able to demonstrate with a vibratory stimulus to the right hand palm of healthy volunteers and $\mathrm{H}_{2}{ }^{15} \mathrm{O}$ PET that activation of some cerebral structures is accompanied by deactivations of corresponding other structures elsewhere in the brain (Seitz and Roland, 1992). Increases in the regional cerebral blood flow were localized in the left primary somatosensory area, the left secondary somatosensory area, the left retroinsular field, the left anterior parietal cortex, the left primary motor area, and the left supplementary motor area. The decreases occurred bilaterally within the superior parietal cortex, paralimbic association areas, and the left globus pallidus. The mean global cerebral blood flow did not change compared with rest. The decreases in cerebral oxidative metabolism were interpreted as regional depressions of synaptic activity.

In an $\mathrm{H}_{2}{ }^{15} \mathrm{O}$ PET study by Drevets et al., changes in the human primary and secondary somatosensory cortices during the period when somatosensory stimuli were expected were investigated (Drevets et al., 1995): In anticipation of either focal or innocuous touching, or localized, painful shocks, the blood flow decreased in the parts of the primary somatosensory cortex located outside the representation of the skin locus of the expected stimulus. Specifically, attending to an impending stimulus to the fingers produced a significant decrease in blood flow in the somatosensory zones for the face, whereas attending to stimulation of the toe produced decreases in the zones for the fingers and face. Decreases were more prominent in the side ipsilateral to the location of the expected stimulus. No significant changes in the blood flow occurred in the region of the cortex representing the skin locus of the expected stimulation. These results were concurrent with a 
model of spatial attention in which potential signal enhancement may rely on generalized suppression of background activity.

In the same year, Ibanez et al. demonstrated in a PET study that there is no evidence that the primary motor and supplementary motor area are involved in the generation of the P22 and N30 components of somatosensory evoked potentials (SSEPs) caused by electrical stimulation of the median nerve at the wrist (Ibanez et al., 1995). PET was performed in normal subjects to study the cerebral areas activated by median nerve electrical stimulation at frequencies of up to $20 \mathrm{~Hz}$. Stimulation evoked a single focus of activation in the primary somatosensory area. An increase of the regional cerebral blood flow in this area was linearly correlated with stimulus frequencies of up to $4 \mathrm{~Hz}$ and then reached a plateau. The supplementary motor area was not significantly activated by stimulation at any of the frequencies tested. In contrast to the primary somatosensory area, the supplementary motor area showed no trend toward a correlation between the regional cerebral blood flow changes and the stimulus repetition rate. These results suggested that a contribution of the primary motor cortex and the supplementary motor area to the generation of the P22 and N30 components of SSEPs is unlikely.

$\mathrm{H}_{2}{ }^{15} \mathrm{O}$ PET studies with different application forms and intensities of innocuous and noxious thermal stimuli were performed by Casey et al (Casey et al., 1994;Casey et al., 1996) to identify the forebrain and brain stem structures that are active during the perception of acute heat pain in humans. Healthy subjects received repetitive noxious $\left(50^{\circ} \mathrm{C}\right)$ and innocuous $\left(40^{\circ} \mathrm{C}\right)$ heat pulses with duration of five seconds to the forearm and each subject rated the subjective intensity of each stimulation series. Significant regional cerebral blood flow with a maximum at $50^{\circ} \mathrm{C}$ stimuli was found in the thalamus, the cingulate cortex, the secondary and primary somatosensory cortex, the insula, the medial dorsal midbrain and the cerebellar vermis. In the second study noxious and innocuous heat and cold thermal stimuli to the non-dominant arm of healthy subjects were applied.

A detailed analysis of somatosensory representations within the parietal postcentral gyral and the lateral sulcal-opercular cortex in a $\mathrm{H}_{2}{ }^{15} \mathrm{O}$ PET study was performed by Burton et al. (Burton et al., 1997). To investigate the issue of possible multiple activation foci in these regions and possible differences due to stimulating skin directly or through an imposed tool, changes in the regional cerebral blood flow during passive tactile stimulation of one or two fingertips were studied. Restrained fingers were rubbed with embossed gratings using a rotating drum stimulator. For different scans, gratings touched the skin directly for optimal stimulation of cutaneous receptors (skin mode stimulation) or indirectly by using an imposed guitar plectrum snugly fitted to the same fingers (tool mode stimulation). The latter was expected to better stimulate deep receptors better. The subjects were asked to estimate the roughness after each scan. Direct skin contact activated statistically validated foci in both hemispheres, on the contralateral side these foci occurred in the anterior and posterior limbs of the postcentral gyrus and on the ipsilateral side only in the posterior limb. Tool mode stimulation activated one contralateral focus that was in the posterior limb of the postcentral gyrus. These results suggested at least two maps for distal fingertips in the primary somatosensory area with the anterior and posterior foci corresponding, respectively, to activations in the Brodmann area $3 \mathrm{~b}$ and the junction between the Brodmann areas 1 and 2 . In the contralateral secondary somatosensory area, skin mode stimulation activated a peak that was anterior and medial to a focus associated with tool mode stimulation. The magnitude of the PET counts contralateral to stimulation was higher in the anterior primary and secondary somatosensory regions during initial scans, but reversed to 
more activation in the posterior primary somatosensory region during later scans. These short-term practice effects suggested changes in neural activity with stimulus novelty.

Another method for selectively activating the cortical projections of deep receptors for proprioceptive perception in a study with $\mathrm{H}_{2}{ }^{15} \mathrm{O}$ PET was presented by Mima et al. (Mima et al., 1999). Functional brain maps during active and passive finger movements driven by a servo-motor were compared. The authors were able to selectively activate proprioception with a minimal contribution from the epicritic sensation with a newly developed device. Proprioception was represented only within the contralateral primary and secondary somatosensory areas, whereas active movements were cortically represented within the contralateral primary sensorimotor cortex, the premotor cortex, the supplementary motor area, the bilateral secondary somatosensory areas, the basal ganglia and the ipsilateral cerebellum. In this study, differential brain maps for cortical representations of different components of the sensorimotor system were displayed for the first time in the field of functional neuroimaging.

$\mathrm{Xu}$ et al. elucidated the functional localization and somatotopic organization of pain perception in the human cerebral cortex with PET during selective painful stimulation. Response to painful stimuli to the hand and foot were elicited using a special $\mathrm{CO}_{2}$ laser, which selectively activates nociceptive receptors (Xu et al., 1997). Multiple brain areas, including the bilateral secondary somatosensory areas and both insulas, the frontal lobe, and thalamus contralateral to the stimulus side were found to be involved in the response to painful stimulation. While the data indicate that the bilateral secondary somatosensory area plays an important role in pain perception, they also indicate that there is no pain-related somatotopic organization in the human secondary somatosensory cortex or insula. Pain processing during three levels of noxious stimulation that produced differential patterns of central activity was investigated by Derbyshire et al. (Derbyshire et al., 1997).

Bittar et al. investigated presurgical mapping of the primary somatosensory cortex compared with intraoperative cortical stimulation with $\mathrm{H}_{2}{ }^{15} \mathrm{O}$ PET (Bittar et al., 1999a;Bittar et al., 1999b). PET scanning with vibrotactile stimulation of the face, the hands or the feet to localize the primary somatosensory area before surgical resection of the mass lesions or epileptogenic foci affecting the central area was performed in patients with brain tumor. With the aid of image-guided surgical systems, the location of significant activation foci on the PET scanning were compared with those of positive intraoperative cortical stimulation performed at craniotomy. In 95\%, the PET activation foci were spatially concordant with the intraoperative cortical stimulation. Intraoperative cortical stimulation was positive in $40 \%$ of the stimulation sites where the PET did not result in statistically significant activation. According to these results, it was concluded that PET is an accurate method for mapping the primary somatosensory area prior to surgery.

Boecker et al. investigated the functional anatomy of somatosensory processing in two clinical conditions characterized by basal ganglia dysfunction in Parkinson's and Huntington's disease (Boecker et al., 1999) in a $\mathrm{H}_{2}{ }^{15} \mathrm{O}$ PET study. Continuous unilateral high-frequency vibratory stimulation was applied to the immobilized metacarpal joint of the index finger. In the control subjects, the activation pattern was lateralized to the side opposite to the stimulus presentation, including the primary and secondary somatosensory areas, as well as subcortical (globus pallidus, ventrolateral thalamus) regions. Inter-group comparisons of the vibration-induced changes of the regional cerebral blood flow between patients and control subjects revealed differences in central somatosensory processing. In Parkinson's disease, decreased activation was found in the contralateral sensorimotor cortex, 
the lateral premotor cortex, the contralateral secondary somatosensory area, the contralateral posterior cingulate cortex, the bilateral prefrontal cortex (Brodmann area 10) and in the contralateral basal ganglia. In Huntington's disease, decreased activation was detected contralateral in the secondary somatosensory area, the parietal Brodmann areas 39 and 40, the lingual gyrus, the bilateral prefrontal cortex (Brodmann areas 8, 9, 10 and 44), the primary somatosensory area, and the contralateral basal ganglia. In both clinical diseases, relative enhanced activation of the ipsilateral somatosensory cortical areas, notably the caudal primary and secondary somatosensory regions as well as the insular cortex, could also be detected. The data show that Parkinson's and Huntington's disease, beyond wellestablished deficits in the central motor control, are characterized by abnormal cortical and subcortical activation on passive somatosensory stimulation. Furthermore, the finding that the activation increases in the ipsilateral somatosensory cortical areas may be interpreted as an indication of either altered central focusing and gating of the somatosensory impulses, or enhanced compensatory recruitment of the somatosensory areas.

A 18 F-fluorodeoxyglucose PET study with somatosensory stimulation in patients suffering from spinal cord injuries was performed by Roelcke et al. (Roelcke et al., 1997a) to assess the effect of a transverse spinal cord lesion on cerebral energy metabolism in view of sensorimotor reorganisation. PET was used to study resting cerebral glucose metabolism in patients with complete paraplegia or tetraplegia after spinal cord injury compared with healthy subjects. The global absolute glucose metabolism rate was lower in the spinal cord injury patients than in the healthy subjects. A relatively increased glucose metabolism was discovered particularly in the supplementary motor area, the anterior cingulate, and the putamen. A relatively reduced glucose metabolism was found in patients with spinal cord injury was found in the midbrain, the cerebellar hemispheres, and the temporal cortex. It was concluded that cerebral deafferentation due to reduction or loss of sensorimotor function results in the low level of an absolute global glucose metabolism rate found in patients with spinal cord injury. Relatively increased glucose metabolism in brain regions involved in attention and initiation of movement may be related to secondary disinhibition of these regions.

PET studies using noxious electrical stimuli to the median nerve were also performed on patients in persistent vegetative state (actually referred to as unresponsive wakefulness syndrome) to assess cortical pain processing (Kassubek et al., 2003; Laureys et al., 2002). Even though cortical metabolism (in FDG-PET) was decreased up to $40 \%$ of normal values, both studies showed reliable activations in residual parts of the pain processing networks in $\mathrm{H}_{2}{ }^{15} \mathrm{O}$ PET. Compared to age-matched controls, noxious stimuli activated the primary somatosensory cortex, contralateral thalamus and midbrain, but failed to activate higherorder associative cortices (secondary somatosensory, bilateral posterior parietal, premotor, polysensory superior temporal and prefrontal cortices). These findings help to understand cortical processing after severe brain injury, however, but they can neither prove nor disprove awareness of pain or any other stimulus in this patient group.

\section{Functional Magnetic Resonance Imaging}

Somatosensory stimuli were applied in many functional magnetic resonance imaging (fMRI) studies. Especially light stimulation using air puffs (Stippich et al., 1999b) or other tactile stimuli (Hodge et al., 1998;Moore et al., 2000;Rausch et al., 1998;Servos et al., 1998), scratching of the hand palm (Hoeller et al., 2002), vibration (Gelnar et al., 1998b;Golaszewski 
et al., 2002;Golaszewski et al., 2006;Golaszewski et al., 2002;Hodge et al., 1998), electrical stimulation (Arthurs et al., 2000;Backes et al., 2000;Korvenoja et al., 1999;Krause et al., 2001;Kurth et al., 1998;Takanashi et al., 2001), noxious stimuli (Apkarian et al., 2000;Peyron et al., 2000), and proprioception induced by passive joint movement (Rausch et al., 1998) were used. Usually, the primary somatosensory cortex in the postcentral gyrus and the secondary somatosensory cortex in the parietal operculum, insula, and more posterior ventral parietal areas are activated. A clear somatotopic organization in the primary somatosensory cortex could be demonstrated, whereas this somatotopic organization could not be clearly shown in the secondary somatosensory area (Disbrow et al., 2000;Gelnar et al., 1998b;Hodge et al., 1998;Krause et al., 2001;Kurth et al., 1998;Servos et al., 1998). An evident somatotopy also in the secondary somatosensory area was demonstrated in a study by Gelnar et al. (Gelnar et al., 1998c). A vibratory stimulus was applied to an individual digit tip (digit 1,2, or 5) on the right hand of healthy adults which led to a BOLD response in cortical regions located on the upper bank of the Sylvian fissure, the insula, and the posterior parietal cortices. Multiple digit representations were observed in the primary somatosensory cortex, corresponding to the four anatomic subdivisions areas $3 a, 3 b, 1$, and 2. There was no simple medial to lateral somatotopic representation in individual fMRI maps but a clear spatial distance between digit 1 and digit 5 was seen on the cortex in both the primary and secondary somatosensory regions. Ruben et al. was able to demonstrate a somatotopic organization of the secondary somatosensory area with electrical stimulation of the right hallux, the index and the fifth finger (Ruben et al., 2001). They were not able to observe separate representations of digit 2 and 5 in the secondary somatosensory area, but a somatotopic representation between the fingers and the hallux could be detected bilaterally within the secondary somatosensory region. Kurth et al. demonstrated a somatotopy in the primary somatosensory cortex by using electrical finger stimulation (Kurth et al., 2000). Functional MRI detected separate representations for all five fingers in the primary somatosensory cortex. Responses were located in the posterior wall of the deep central sulcus (corresponding to Brodmann area $3 b$ ), and the anterior (Brodmann area 1) or the posterior crown of the postcentral gyrus (Brodmann area 2) with rare activations in Brodmann area $3 \mathrm{a}$ and 4 . In Brodmann area $3 \mathrm{~b}$, a regular somatotopic mediolateral digit arrangement for fingers 5 to 1 with a mean Euclidean distance of $16 \mathrm{~mm}$ between fingers 1 and 5 was found. In contrast, Brodmann area 1 and 2 showed a greater number of adjacent activation foci with a significantly greater overlap and partly even reversed ordering of the neighboring fingers. This paradigm can be used to localize the central sulcus preoperatively (Kurth et al., 1998) and it is applicable even in patients with severe hemiparesis without severe hemianesthesia.

In many studies investigating the primary somatosensory cortex, only a contralateral BOLD response could be elicited, whereas the secondary somatosensory areas were activated bilaterally (Backes et al., 2000;Disbrow et al., 2001;Korvenoja et al., 1999). It is still uncertain, what stimulus leads to the most robust BOLD response within the somatosensory cortex. There is evidence that pain stimuli are less reliable than vibrotactile or electrical stimuli for evoking primary somatosensory activation (Backes et al., 2000;Disbrow et al., 2001;Korvenoja et al., 1999;Peyron et al., 2000). Activation magnitude in the primary somatosensory cortex depends on the intensity of stimulation (Arthurs et al., 2000;Krause et al., 2001), the size of the stimulated body surface (Apkarian et al., 2000;Peyron et al., 2000), and the rate of stimulation (Apkarian et al., 2000;Peyron et al., 2000;Takanashi et al., 2001). Nelson et al. demonstrated an increasing stimulus-response relationship between the 
amplitude of vibrotactile stimuli delivered to the volar surface of the right index finger and BOLD activity in the primary somatosensory area that persisted during an attentiondemanding tactile tracking task (Nelson et al., 2004). The secondary somatosensory cortex did not show any clear relationship with the vibration amplitude, but was more often activated during the attention demanding tracking task compared with passive vibration. Responses in secondary areas seem to be less influenced by these variables, but are probably more dependant of the level of attention directed to the stimulus (Apkarian et al., 2000;Backes et al., 2000;Peyron et al., 2000;Takanashi et al., 2001) and on whether stimulation is delivered uni- or bilaterally (Apkarian et al., 2000;Backes et al., 2000;Disbrow et al., 2001;Peyron et al., 2000;Takanashi et al., 2001). Regarding attentional phenomena interfering with somatosensory processing, tactile processing while varying the focus of attention was studied. Activations were contrasted between attend and ignore conditions, both of which employed identical stimulation characteristics and an active task. Random effects analysis revealed significant attention effects in the primary somatosensory area. The blood oxygenation level-dependent response was greater for attended than for ignored stimuli. Modulations were also found in the secondary somatosensory cortex and the middle temporal gyrus. These findings suggest that the stimulus processing at the level of the primary representations in the primary somatosensory area is modulated by attention (Sterr et al., 2007).

Somatosensory stimulation has the advantage of not requiring movement which may cause artifacts. With somatosensory stimulation (repetitive brushing of the hand palm) in brain tumor patients, a lower incidence of severe movement artifacts was found compared to an active motor paradigm (finger-to-thumb-tapping), however, the motor paradigm elicited a significantly higher percentage of signal increases. (Apkarian et al., 2000;Backes et al., 2000;Disbrow et al., 2001;Hoeller et al., 2002;Peyron et al., 2000;Takanashi et al., 2001). Several fMRI studies discovered a similar functional localisation comparing somatosensory stimulation and active motor paradigms (Golaszewski et al., 2002;Golaszewski et al., 2006;Golaszewski et al., 2002;Lee et al., 1998). Lee et al. (1998) demonstrated in an fMRI study similar results with active and passive activation tasks by comparing palm-finger brushing with sponge-squeezing and active finger movements according to their functional localisation. The sensorimotor and somatosensory BOLD responses were located to a large extent in the postcentral gyrus, and their spatial locations were not significantly different. Golaszewski et al. showed largely similar functional maps by active finger-to-thumb tapping and vibration of the hand palm (Golaszewski et al., 2002a;Golaszewski et al., 2002b). In patients who are physically unable to perform active finger-to-thumb-tapping, hand-squeezing or fist clenching as sensorimotor activation tasks the vibration of the hand palm can be regarded as a proper paradigm in presurgical fMRI mapping of the sensorimotor hand area.

In an fMRI study with a piezoelectric vibration device Francis et al. found a frequency dependence of the primary and secondary somatosensory area (Francis et al., 2000). With both frequencies applied to the index finger during the same scanning session, an increase in the vibration frequency from 30 to $80 \mathrm{~Hz}$ showed a significant increase of the BOLD response within the secondary somatosensory area and the posterior insula, while the number of pixels activated in the primary somatosensory area declined.

Moreover, functional imaging studies are important for the monitoring of rehabilitation and the understanding of motor recovery after cortical strokes (Cramer et al., 2000). Functional MRI was used to compare sensory and motor maps obtained in normal controls with 
functional maps from two patients with good recovery six months after a cortical stroke. Cortical map reorganization along the detected infarct rim might be an important contributor to recovery of motor and sensory function after stroke. Moreover, functional imaging studies with somatosensory stimulation are also important for the monitoring of the rehabilitation after extremity transplantations (Piza, 2000). A close relationship between the intensity of phantom limb pain in amputees and the amount of reorganization of the somatosensory cortex was reported in fMRI studies (Flor et al., 2001;Hamzei et al., 2001;Koppelstaetter et al., 2007).

Functional MRI was also used to investigate brain activations underlying menthol-induced cold allodynia (Seifert and Maihöfner, 2007). Healthy volunteers were investigated using a block-design fMRI approach. Brain activity was measured during application of innocuous cold stimuli $\left(5^{\circ} \mathrm{C}\right.$ above cold pain threshold) and noxious cold stimuli $\left(5^{\circ} \mathrm{C}\right.$ below cold pain threshold) to the skin of the forearm using a peltier-driven thermostimulator. The stimuli were adjusted to the individual cold pain threshold. Cold allodynia was induced by topical menthol and cortical activations were measured during previously innocuous cold stimulation $\left(5^{\circ} \mathrm{C}\right)$ that was at this situation perceived as painful. On a numeric rating scale for pain (0-10) innocuous cold, cold pain and cold allodynia were rated. Sensory and affective components of allodynia and cold pain were equal in the McGill pain questionnaire (Roelcke et al., 1997b). All tested conditions (innocuous cold, noxious cold and cold allodynia) led to significant activations of the bilateral insular cortices, the bilateral frontal cortices and the anterior cingulate cortex. When compared with innocuous cold, noxious cold led to significantly more activations of the posterior insula and to less activations of the ipsilateral insular cortex.

Significantly increased activations in bilateral dorsolateral prefrontal cortices and brainstem (ipsilateral parabrachial nucleus) were found during cold allodynia when compared with equally intense cold pain conditions. Cold allodynia led to significantly more activations of the bilateral anterior insula, whereas the activation of the contralateral posterior insula was equal. It was concluded that cold allodynia activates a network similar to that of normal cold pain, but additionally recruits bilateral dorsolateral prefrontal cortex and the midbrain, suggesting that these brain areas are involved in central nociceptive sensitization processes.

In the authors' facility, somatosensory stimulation is also used in the clinical routine to assess patients with chronic disorders of consciousness (unresponsive wakefulness syndrome, minimally conscious state) in fMRI (unpublished data). In a series of 22 consecutive patients with chronic disorders of consciousness, seven patients showed reliable response in typical brain areas using a pneumatic activation device (Figure 3, 4, 6). The above-mentioned somatosensory assessment combined with cognitive testing in functional neuroimaging is routinely acquired in patients with chronic disorders of consciousness for the planning of neurorehabilitation and estimation of prognosis.

\section{Current devices for somatosensory stimulation}

Next to the classical electrical nerve stimulation, vibrotactile stimulation has become very common in functional brain imaging. Vibrotactile stimulation has several advantages over electrical stimulation. First, the stimuli are not painful and therefore a certain stimulus can be presented over a long time period. This is often necessary to obtain a stable cortical 
response. Second, by selecting the site and frequency of the stimulus, the different receptor types (cutaneous mechanoreceptors, proprioceptors, thermo receptors) can be specifically excited and their functional integration at the cortical level can be studied. Third, the stimulus response underlies adaptation which can be used to analyze the somatosensory information processing, its influence to cortical structures, and the modulation by other brain regions (Giabbiconi et al., 2007). On the other hand, a cortical response may be affected adversely by somatosensory adaptation phenomena. This has to be considered when designing a specific stimulation protocol.

In clinical routine, the vibrotactile sense is assessed by brushing on a certain body region (Frey hair) or by using a tuning fork. These manual stimulations were used in the earlier studies of somatotopic mapping (Polonara et al., 1999). However, for more complex stimulation designs, it is more convenient to use quantitative testing equipment. Within the past ten years, various prototypes of stimulation devices have been tested for somatotopic mapping. Among these devices, pneumatically driven air bags were introduced (Gelnar et al., 1998b;Golaszewski et al., 2002a;Stippich et al., 1999b), as well as piezodisks (Harrington et al., 2000b;Maldjian et al., 1999b), cable driven rotating masses (Golaszewski et al., 2002b) and even coil designs using the static magnetic field of an MR scanner (Graham et al., 2001). As most of these devices were used in fMRI-paradigms, the interactions between MRI and the certain stimulation device must be considered. In this chapter, we first focus on the MR compatibility and the MR safety and subsequently give an overview on the different types of devices.

\subsection{MR compatibility and MR safety}

According to the safety guidelines by General Electric (GE) Medical Systems (GE-Medical Systems, 1997), a device is considered to be MR save, if it can be demonstrated that it does not lead to an increased safety risk towards the patient and the staff, when the device is introduced or used in the MR scanner room. For a certain device to be labeled MR compatible, it has to be demonstrated that it performs in its intended function without performance degradation. For the MR compatibility, effects on the devices and effects on the imaging have to be differentiated (Chinzei et al., 1999). These devices are influenced by induced static magnetization as well as torque and translational forces (see Figure 1). Both effects influence the performance of devices containing ferromagnetic materials. Standard springs made of metal do not function as expected. According to the guidelines mentioned above, devices containing ferromagnetic materials should be operated behind the 20-mT line. In this zone, the effects on the devices are irrelevant. However, the risk that such a device is pulled towards the scanner bore (projectile effect) still is high. For safety reasons, not permanently fixed electromagnetic devices should be operated only behind the 5-mT line. The imaging quality is degraded by field inhomogenities and RF (radio frequency) emission (see Figure 1). Static field inhomogenities come from the ferromagnetic materials contained in the devices, but in most cases the image quality can be restored after shimming the magnet. RF is typically produced by pulsed electronics and the digital hardware emitted by the cables of the device. As MRI is highly sensitive to RF noise, such devices have to be operated outside the MR scanner room. On the other hand, small amplitude electromagnetic fields up to some hundred $\mathrm{Hz}$, as produced by some vibrotactile stimulation devices, only showed minor effects on imaging. 


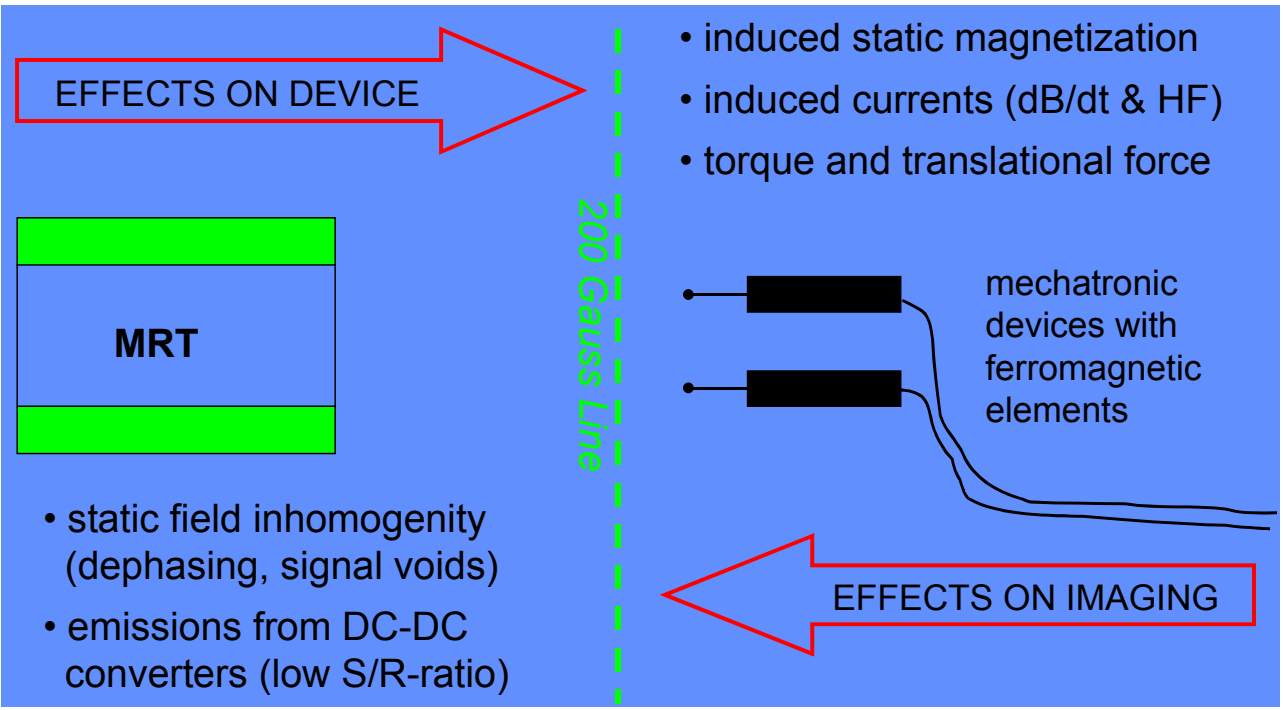

Fig. 1. Overview on MR-compatibility (GE Medical Systems. MR safety and MR compatibility. http://www.ge.com/medical/mr/iomri/safety.htm; 1997).

\subsection{Principles and technical designs}

For somatosensory mapping, well-controlled and reproducible stimuli are required. Principally, this can be achieved by using pneumatic, piezoceramic and electromechanical devices. Concerning MR compatibility and safety, pneumatic devices are the best choice. The hardware of a pneumatic stimulation device typically consists of a pressure source, a valve for converting the air stream into the desired pressure oscillations and a vibrotactile display to deliver the stimuli to the skin surface. As vibrotactile probe, a latex balloon, a pickup with an integrated rubber membrane (Briggs et al., 2004), or an injector element to produce air puffs was described (Huang and Sereno, 2007). The pressure oscillations are transmitted to the vibrotactile display via long plastic tubes so that all other components of the device can be operated outside of the MR scanner room. However, pneumatic systems have the disadvantage of limited vibration frequencies. Due to the mechanical damping of the pressure oscillations in the plastic tubes the stimulus frequency is limited to about $30 \mathrm{~Hz}$. Higher stimulation frequencies can be achieved by using nonmagnetic valves, suited for operation inside the MR scanner room. Multi-channel stimulation designs are feasible with multiple valves and pickups (Wienbruch et al., 2006). Pneumatic devices have shown to cause somatosensory brain activation, but failed to additionally activate motor cortical areas in somatosensory paradigms.

Piezoceramic devices provide a wide range of frequencies, but only have small displacement amplitudes, which limits their application to the skin receptors. Stimulation frequencies up to $1000 \mathrm{~Hz}$ can be obtained. The vibration amplitude achieved by these devices is limited to some hundred $\mu \mathrm{m}$ and even for this relative high operation voltages (up to 200 Volts) are necessary. Because these devices are nonmagnetic, they can be operated inside the MR scanner room. Basically, bar- and disk-like actuators as well as piezomotors are available. The bar- and the disk-like actuators directly convert the 
electrical signal into bending motions (Piezomechanik Gmbh, 2002). For stimulation applications, these devices can either be held between the fingertips (Harrington et al., $2000 \mathrm{~b}$ ) or touched by the fingertips (Maldjian et al., 1999b). Functional MRI with piezoceramic vibrators showed brain activation within the somatosensory cortex but not within motor cortical areas (Harrington et al., 2000a). It is important to avoid loops in the cables, because this may lead to currents from the RF- and gradient coils. These may cause heat and even fire hazard. There is less data with piezomotors. Basically, piezomotors are well suited for construction of MR compatible robotic stimulation devices, for example to induce passive limb motions. For their operation, high driving frequencies $(>40 \mathrm{kHz})$ are necessary, therefore effects on the MR imaging have to be considered, when using such devices (Chinzei et al., 1999).

Electromagnetic stimulation devices may be classified into three groups depending on the vicinity to the MR scanner at their operation. In the first group, there is common standard equipment containing motors or actuators with pulsed electronics. Such equipment causes RF-emission and therefore has to be operated outside the shielded area of the MR scanner room. For vibrotactile stimulation long cables are needed to transmit the stimulus from the outside to the subject. Cable driven rotating eccentric masses are an example for such type of stimulation device. A frequency range between 1-130 Hz and displacement amplitudes up to $4 \mathrm{~mm}$ can be reached. In an fMRI study implementing this technique, BOLD responses within the somatosensory as well as the motor cortical areas could be demonstrated (Golaszewski et al., 2002b). The second group consists of non-switched moving magnet, and moving coil devices, which can be operated inside the scanner behind the 20-mT line (Golaszewski et al., 2006;Gallasch et al., 2006). With this technique, the parameters of a stimulus (amplitude, frequency, waveform) can be selected within a wide range, which is advantageous for basic investigations. On the other hand, these devices also need some mechanics for translating the stimulus to the subject under investigation. When these mechanic parts are made of metallic materials, the device will also influence the imaging and itself be influenced by the magnetic field. In the third group of somatosensory stimulation, the devices comprise coil actuators utilizing the static magnetic field of the MR scanner. By applying currents to a coil, Lorenz forces generate vibration (Graham et al., 2001), as well as load and movement (Riener et al., 2005). This type of actuator-stimulator is suited for the operation inside the MR scanner, but it is important to be careful in order to prevent heating of the coils due to induced currents.

\subsection{Device for stimulation of the foot sole}

A recently developed stimulator for the foot sole is described here as an example for an electromechanical device to be operated inside the scanner room (Gallasch et al., 2006). It consists of two moving magnet actuators rigidly connected on a platform by two nonmagnetic adjustable stands (see Figure 2). To preserve MR compatibility (operation behind the $20-\mathrm{mT}$ line) the foot sole is contacted via long indentors $(30 \mathrm{~cm})$. Further, to avoid effects on imaging, the actuators are powered by non-pulsed servo amplifiers. All other components containing pulsed electronics (digital controller and PC) are operated outside the MR scanner room. For stimulation of slowly and rapid adapting mechanoreceptors a mixed open and closed loop control scheme was implemented. Slowly adapting receptors respond to nearly static loading $(0-1 \mathrm{~Hz})$. This is achieved by 
an open loop programming of the contact force $(0-20 \mathrm{~N})$. Rapid adapting receptors respond to vibration, which is achieved by the closed loop control scheme. With the implemented controller arbitrary vibration waveforms within the frequency band of 20 to $100 \mathrm{~Hz}$ can be generated. A computer is used for stimulus synthesis, sequencing of the stimuli and synchronization with the MR scans. The first MRI studies with this device show that specially designed electromagnetic devices are well suited for somatotopic mapping.

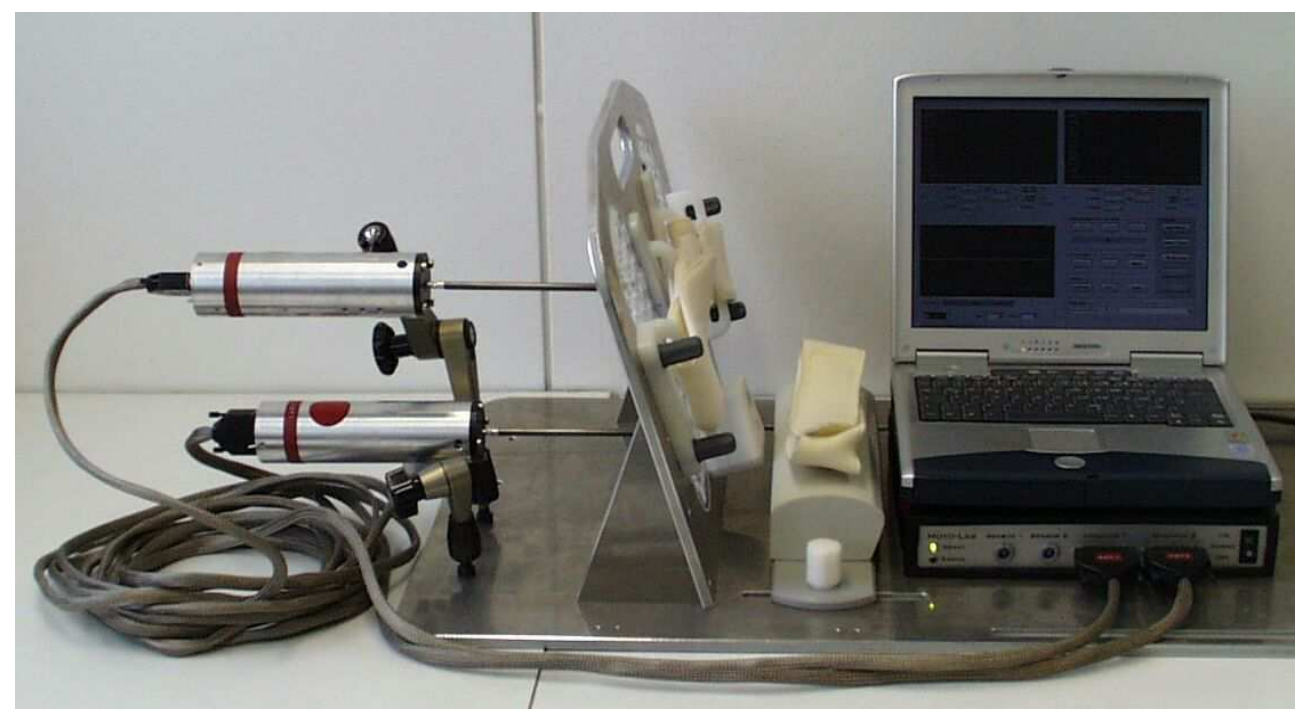

Fig. 2. Example of an electromagnetic vibrotactile stimulation system (Gallasch et al., 2006).

\subsection{Perspectives}

Recently, various types of stimulation devices were evaluated for somatotopic mapping. Although substantial physiological results have been obtained with some of these devices, this technology still needs to be improved. Clinicians expect equipment for quantitative sensory testing, which is safe and simple to use. Other systems will be needed for stimulation of the entire spectrum of somatosensory fibers. These are the large diameter Abeta fibers mediating touch and vibration, the smaller A-delta fibers mediating cool sensation and the first signs of pain, and the small diameter C-fibers mediating sensation of heat and pain. We therefore suggest a bimodal stimulation system to deliver with both vibrotactile and temperature stimuli. For the sole of the foot, such a system may have an arrangement as shown in Figure 2 with additional Peltier elements on the tip of the indentors, however with pneumatic actuators instead of the electromagnetic ones. For hand and fingers wearable stimulation devices are prospective, e.g. pneumatic finger or toe cuffs (Gallasch et al., 2010;Figure 3, 4, 5) or some kind of stimulation glove with pressurized sections at the fingertips including flat shaped heat pipes for quick cooling and warming. For the usage as a clinical tool, further multicenter studies with standardized stimulation protocols have to be carried out. Such studies are necessary to establish stable stimulusresponse relationships independent of a certain scanner type. 


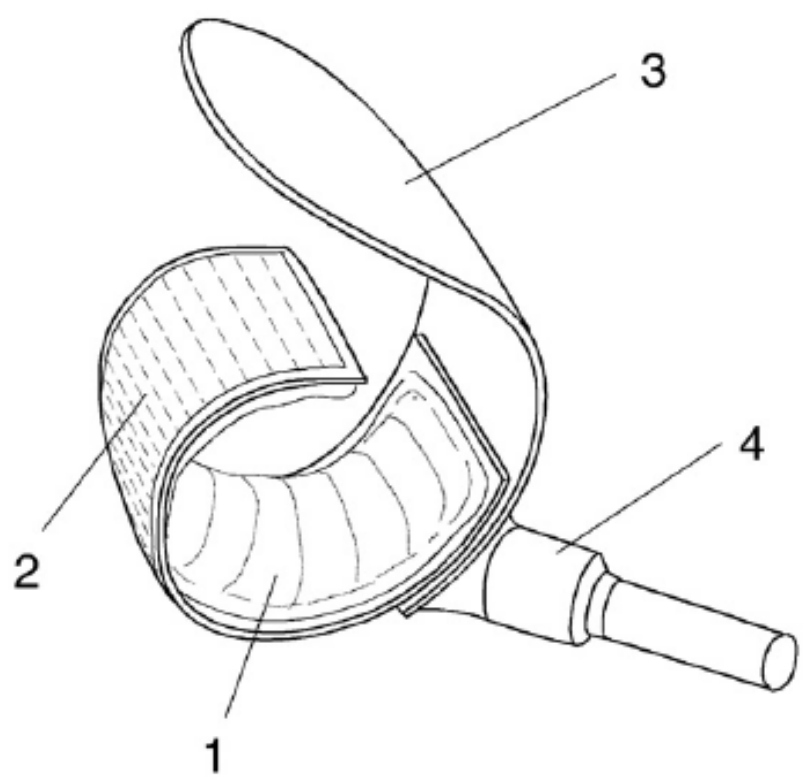

Fig. 3. Drawing of finger cuff with inflatable air bladder (1), flexible Welco strips $(2,3)$ and air connector (4)

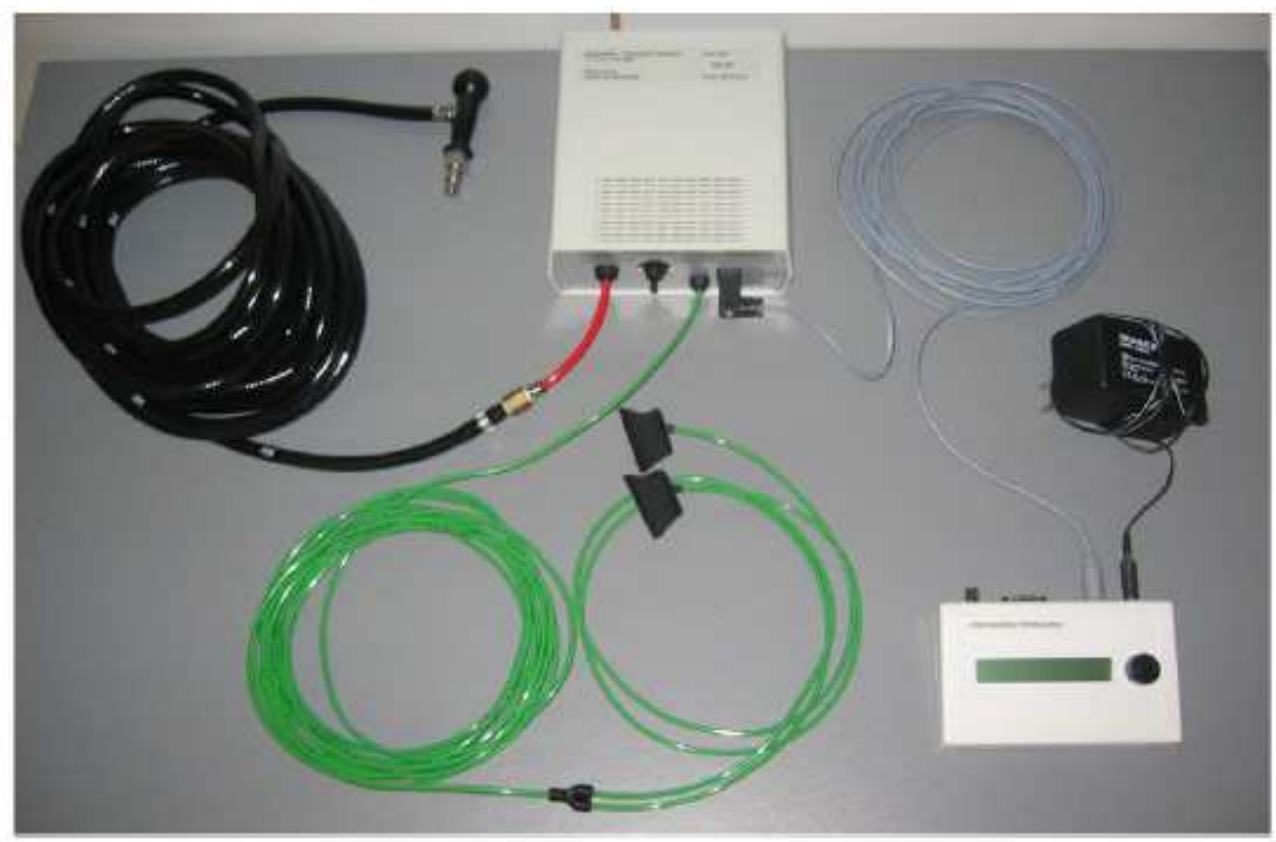

Fig. 4. Stimulator system consisting of twin finger cuff, valve box and microprocessor unit. 


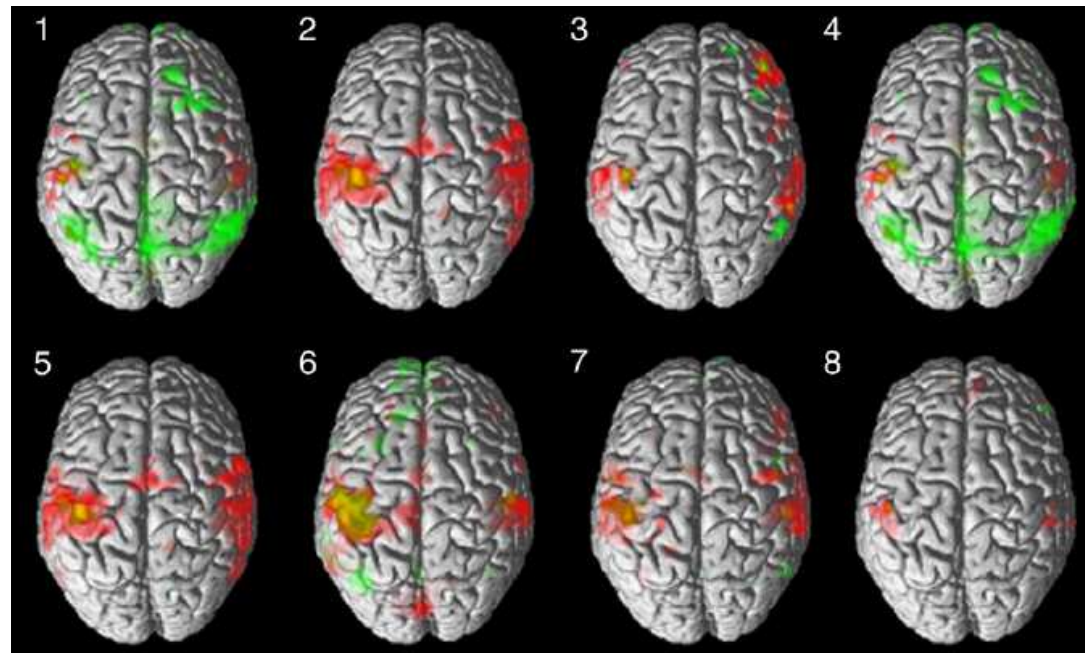

Fig. 5. Single subject analysis: fMRI maps of eight single subjects (1-8) applying pneumatic cuff somatosensory finger stimulation with fixed (fixed simulation FS, green) and random (random stimulation RS, red) presentation of vibrotactile stimuli with a mean frequency of 4 $\mathrm{Hz}$ over all blocks. Yellow spots represent activation overlap between FS and RS maps

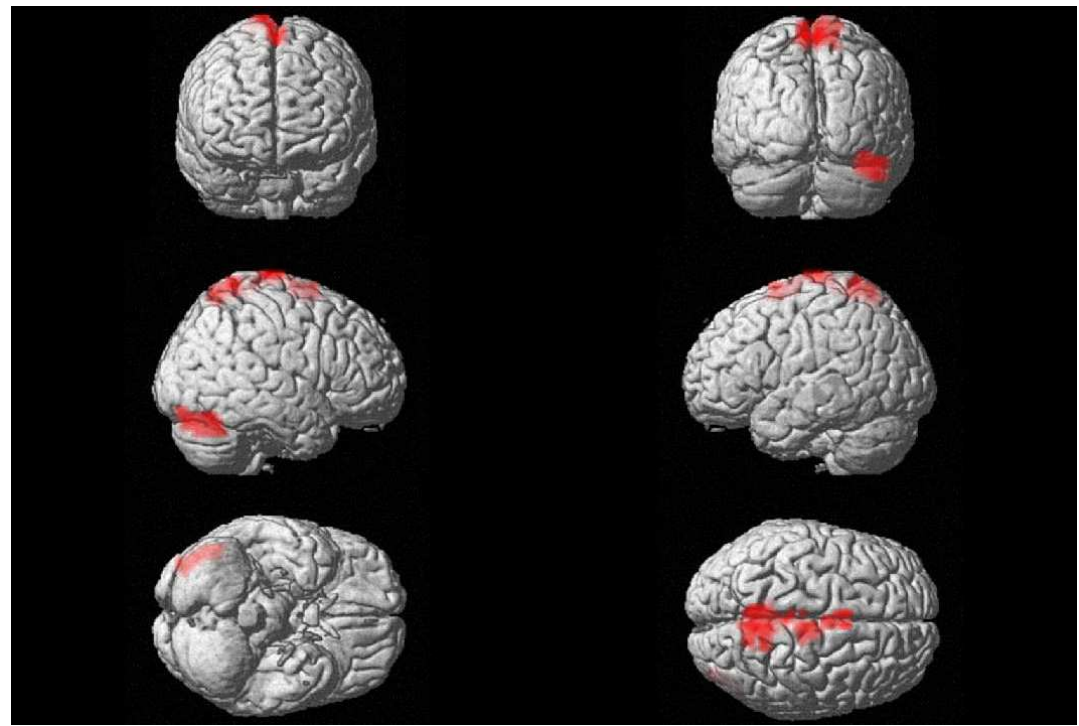

Fig. 6. Patient in vegetative state 14 days post hypoxia. Vibration stimulation with a moving magnet actuator system delivered to the sole of the left foot (Gallasch et al., 2006;Golaszewski et al., 2006) elicits brain activation contra- and ipsilaterally within the primary and secondary sensorimotor cortex and especially within the premotor cortex, the center for predefined movement loops, and the supplementary motor area that represents the superior center for motor planning. Functional brain mapping in this patient proved an intact somatosensory channel to the sensorimotor system for a targeted therapeutic approach in neurorehabilitation. 


\section{Perspective of the application of somatosensory stimulation within the clinical environment}

In the studies of Gelnar, Harrington, and Stippich et al., brain activation within the postcentral gyrus and superior and inferior parietal lobule have been found (Gelnar et al., 1998a;Harrington et al., 2000a;Stippich et al., 1999a). Furthermore, brain activation within Brodmann area 3a was detected due to somatosensory stimulation (Geyer et al., 1999;Geyer et al., 2000;Kurth et al., 2000), which can be explained by the fact that Brodmann area 3a receives input from the deep and from the proprioceptive receptors (Ibanez et al., 1989;Iwamura et al., 1993;Kaas et al., 1979;Maldjian et al., 1999a;Recanzone et al., 1992; Tharin and Golby, 2007). BOLD response in the primary motor cortex due to vibrotactile stimulation is an important finding, because the stimulation does not require the collaboration of the subject under examination. In an fMRI study with mechanical vibration, BOLD response in primary sensorimotor cortex was found in all of the investigations (Golaszewski et al., 2002a,b). Motor cortical activation caused by vibration, is presumably based on the co-stimulation of cutaneous mechanoreceptors and muscle spindles that requires sufficient displacement amplitudes and vibration frequencies. Similar to the fingerto-thumb-tapping paradigm, vibration led to contralateral brain activity in postcentral gyrus in ten out of ten subjects. Vibration stimulation failed to consistently activate supplementary motor area and anterior cingular cortex since it represents a passive paradigm that does not involve motor cortical areas for planning of volitional movements. Vibratory stimuli are transmitted via the large afferents of the dorsal column to the thalamus and are relayed there to the brain cortex. This "information" originates from the extra personnel space that might be an explanation, why Brodmann area 9 in superior frontal gyrus responds with activation in some cases.

In functional brain imaging with certain somatosensory stimulation protocols the whole sensorimotor cortex can be addressed for functional brain mapping that offers the possibility of several clinical applications for somatosensory paradigms in Neuroradiology. Somatosensory paradigms can be used for preoperative functional brain mapping of the sensorimotor cortex in patients with perirolandic lesions. Further applications include the investigation of brain plasticity and reorganization (Pons et al., 1992) and investigation of patients in comatose and vegetative state (Kampfl et al., 1998).

\section{References}

Apkarian, A.V., Gelnar, P.A., Krauss, B.R., and Szeverenyi, N.M. (2000). Cortical responses to thermal pain depend on stimulus size: a functional MRI study. J Neurophysiol $83,3113-22$.

Arthurs, O.J., Williams, E.J., Carpenter, T.A., Pickard, J.D., and Boniface, S.J. (2000). Linear coupling between functional magnetic resonance imaging and evoked potential amplitude in human somatosensory cortex. Neuroscience 101, 803-6.

Backes, W.H., Mess, W.H., van Kranen-Mastenbroek, V., and Reulen, J.P. (2000). Somatosensory cortex responses to median nerve stimulation: fMRI effects of current amplitude and selective attention. Clin Neurophysiol 111, 1738-44.

Bittar, R.G., Olivier, A., Sadikot, A.F., Andermann, F., Comeau, R.M., Cyr, M., Peters, T.M., and Reutens, D.C. (1999a). Localization of somatosensory function by using 
positron emission tomography scanning: a comparison with intraoperative cortical stimulation. J Neurosurg 90, 478-83.

Bittar, R.G., Olivier, A., Sadikot, A.F., Andermann, F., Pike, G.B., and Reutens, D.C. (1999b). Presurgical motor and somatosensory cortex mapping with functional magnetic resonance imaging and positron emission tomography. J Neurosurg 91, 915-21.

Boecker, H., Ceballos-Baumann, A., Bartenstein, P., Weindl, A., Siebner, H.R., Fassbender, T., Munz, F., Schwaiger, M., and Conrad, B. (1999). Sensory processing in Parkinson's and Huntington's disease: investigations with 3D H(2)(15)O-PET. Brain 122 ( Pt 9), 1651-65.

Briggs, R.W., Dy-Liacco, I., Malcolm, M.P., Lee, H., Peck, K.K., Gopinath, K.S., Himes, N.C., Soltysik, D.A., Browne, P., and Tran-Son-Tay, R. (2004). A pneumatic vibrotactile stimulation device for fMRI. Magn Reson Med 51, 640-3.

Burton, H., MacLeod, A.M., Videen, T.O., and Raichle, M.E. (1997). Multiple foci in parietal and frontal cortex activated by rubbing embossed grating patterns across fingerpads: a positron emission tomography study in humans. Cereb Cortex 7, 3-17.

Casey, K.L., Minoshima, S., Berger, K.L., Koeppe, R.A., Morrow, T.J., and Frey, K.A. (1994). Positron emission tomographic analysis of cerebral structures activated specifically by repetitive noxious heat stimuli. J Neurophysiol 71, 802-7.

Casey, K.L., Minoshima, S., Morrow, T.J., and Koeppe, R.A. (1996). Comparison of human cerebral activation pattern during cutaneous warmth, heat pain, and deep cold pain. J Neurophysiol 76, 571-81.

Chinzei, K., Kikinis, R., and Jolesz, F. (1999). MR compatibility of mechanotronic devices, design criteria. In Proc MICCA 99, Lecture Notes in Computer Science 1679, 1020-1031.

Cramer, S.C., Moore, C.I., Finklestein, S.P., and Rosen, B.R. (2000). A pilot study of somatotopic mapping after cortical infarct. Stroke 31, 668-71.

Derbyshire, S.W., Jones, A.K., Gyulai, F., Clark, S., Townsend, D., and Firestone, L.L. (1997). Pain processing during three levels of noxious stimulation produces differential patterns of central activity. Pain 73, 431-45.

Disbrow, E., Roberts, T., and Krubitzer, L. (2000). Somatotopic organization of cortical fields in the lateral sulcus of Homo sapiens: evidence for SII and PV. J Comp Neurol 418, 1-21.

Disbrow, E., Roberts, T., Poeppel, D., and Krubitzer, L. (2001). Evidence for interhemispheric processing of inputs from the hands in human S2 and PV. J Neurophysiol 85, 2236-44.

Drevets, W.C., Burton, H., Videen, T.O., Snyder, A.Z., Simpson, J.R. Jr, and Raichle, M.E. (1995). Blood flow changes in human somatosensory cortex during anticipated stimulation. Nature 373, 249-52.

Flor, H., Denke, C., Schaefer, M., and Grusser, S. (2001). Effect of sensory discrimination training on cortical reorganisation and phantom limb pain. Lancet 357, 1763-4.

Fox, P.T., Burton, H., and Raichle, M.E. (1987). Mapping human somatosensory cortex with positron emission tomography. J Neurosurg 67, 34-43.

Francis, S.T., Kelly, E.F., Bowtell, R., Dunseath, W.J., Folger, S.E., and McGlone, F. (2000). fMRI of the responses to vibratory stimulation of digit tips. Neuroimage 11, 188-202.

Gallasch, E., Fend, M., Rafolt, D., Nardone, R., Kunz, A., Kronbichler, M., Beisteiner, R., and Golaszewski, S. (2010). Cuff-type pneumatic stimulator for studying somatosensory evoked responses with fMRI. Neuroimage 50, 1067-73.

Gallasch, E., Golaszewski, S.M., Fend, M., Siedentopf, C.M., Koppelstaetter, F., Eisner, W., Gerstenbrand, F., and Felber, S.R. (2006). Contact force- and amplitude-controllable 
vibrating probe for somatosensory mapping of plantar afferences with fMRI. J Magn Reson Imaging 24, 1177-82.

GE Medical Systems. MR safety and MR compatibility. http://www.ge.com/medical/mr/iomri/safety.htm; 1997.

Gelnar, P.A., Krauss, B.R., Szeverenyi, N.M., and Apkarian, A.V. (1998a). Fingertip representation in the human somatosensory cortex: an fMRI study. Neuroimage 7 , 261-83.

Gelnar, P.A., Krauss, B.R., Szeverenyi, N.M., and Apkarian, A.V. (1998b). Fingertip representation in the human somatosensory cortex: an fMRI study. Neuroimage 7 , 261-83.

Gelnar, P.A., Krauss, B.R., Szeverenyi, N.M., and Apkarian, A.V. (1998c). Fingertip representation in the human somatosensory cortex: an fMRI study. Neuroimage 7, 261-83.

Geyer, S., Schleicher, A., and Zilles, K. (1999). Areas 3a, 3b, and 1 of human primary somatosensory cortex. Neuroimage 10, 63-83.

Geyer, S., Schormann, T., Mohlberg, H., and Zilles, K. (2000). Areas 3a, 3b, and 1 of human primary somatosensory cortex. Part 2. Spatial normalization to standard anatomical space. Neuroimage 11, 684-96.

Giabbiconi, C.M., Trujillo-Barreto, N.J., Gruber, T., and Muller, M.M. (2007). Sustained spatial attention to vibration is mediated in primary somatosensory cortex. Neuroimage 35, 255-62.

Golaszewski, S.M., Siedentopf, C.M., Baldauf, E., Koppelstaetter, F., Eisner, W., Unterrainer, J., Guendisch, G.M., Mottaghy, F.M., and Felber, S.R. (2002b). Functional magnetic resonance imaging of the human sensorimotor cortex using a novel vibrotactile stimulator. Neuroimage 17, 421-30.

Golaszewski, S.M., Siedentopf, C.M., Baldauf, E., Koppelstaetter, F., Eisner, W., Unterrainer, J., Guendisch, G.M., Mottaghy, F.M., and Felber, S.R. (2002). Functional magnetic resonance imaging of the human sensorimotor cortex using a novel vibrotactile stimulator. Neuroimage 17, 421-30.

Golaszewski, S.M., Siedentopf, C.M., Koppelstaetter, F., Fend, M., Ischebeck, A., GonzalezFelipe, V., Haala, I., Struhal, W., Mottaghy, F.M., Gallasch, E., Felber, S.R., and Gerstenbrand, F. (2006). Human brain structures related to plantar vibrotactile stimulation: a functional magnetic resonance imaging study. Neuroimage 29, 923-9.

Golaszewski, S.M., Zschiegner, F., Siedentopf, C.M., Unterrainer, J., Sweeney, R.A., Eisner, W., Lechner-Steinleitner, S., Mottaghy, F.M., and Felber, S. (2002a). A new pneumatic vibrator for functional magnetic resonance imaging of the human sensorimotor cortex. Neurosci Lett 324, 125-8.

Golaszewski, S.M., Zschiegner, F., Siedentopf, C.M., Unterrainer, J., Sweeney, R.A., Eisner, W., Lechner-Steinleitner, S., Mottaghy, F.M., and Felber, S. (2002). A new pneumatic vibrator for functional magnetic resonance imaging of the human sensorimotor cortex. Neurosci Lett 324, 125-8.

Graham, S.J., Staines, W.R., Nelson, A., Plewes, D.B., and McIlroy, W.E. (2001). New devices to deliver somatosensory stimuli during functional MRI. Magn Reson Med 46, 436-42.

Hamzei, F., Liepert, J., Dettmers, C., Adler, T., Kiebel, S., Rijntjes, M., and Weiller, C. (2001). Structural and functional cortical abnormalities after upper limb amputation during childhood. Neuroreport 12, 957-62.

Harrington, G.S., Wright, C.T., and Downs, J.H. 3rd (2000a). A new vibrotactile stimulator for functional MRI. Hum Brain Mapp 10, 140-5. 
Harrington, G.S., Wright, C.T., and Downs, J.H. 3rd (2000b). A new vibrotactile stimulator for functional MRI. Hum Brain Mapp 10, 140-5.

Hodge, C.J. Jr, Huckins, S.C., Szeverenyi, N.M., Fonte, M.M., Dubroff, J.G., and Davuluri, K. (1998). Patterns of lateral sensory cortical activation determined using functional magnetic resonance imaging. J Neurosurg 89, 769-79.

Hoeller, M., Krings, T., Reinges, M.H., Hans, F.J., Gilsbach, J.M., and Thron, A. (2002). Movement artefacts and MR BOLD signal increase during different paradigms for mapping the sensorimotor cortex. Acta Neurochir (Wien) 144, 279-84; discussion 284.

Huang, R.S. and Sereno, M.I. (2007). Dodecapus: An MR-compatible system for somatosensory stimulation. Neuroimage 34, 1060-73.

Ibanez, V., Deiber, M.P., and Mauguiere, F. (1989). Interference of vibrations with input transmission in dorsal horn and cuneate nucleus in man: a study of somatosensory evoked potentials (SEPs) to electrical stimulation of median nerve and fingers. Exp Brain Res 75, 599-610.

Ibanez, V., Deiber, M.P., Sadato, N., Toro, C., Grissom, J., Woods, R.P., Mazziotta, J.C., and Hallett, M. (1995). Effects of stimulus rate on regional cerebral blood flow after median nerve stimulation. Brain 118 ( Pt 5), 1339-51.

Iwamura, Y., Tanaka, M., Sakamoto, M., and Hikosaka, O. (1993). Rostrocaudal gradients in the neuronal receptive field complexity in the finger region of the alert monkey's postcentral gyrus. Exp Brain Res 92, 360-8.

Kaas, J.H., Nelson, R.J., Sur, M., Lin, C.S., and Merzenich, M.M. (1979). Multiple representations of the body within the primary somatosensory cortex of primates. Science 204, 521-3.

Kampfl, A., Schmutzhard, E., Franz, G., Pfausler, B., Haring, H.P., Ulmer, H., Felber, S., Golaszewski, S., and Aichner, F. (1998). Prediction of recovery from post-traumatic vegetative state with cerebral magnetic-resonance imaging. Lancet 351, 1763-7.

Kassubek, J., Juengling, F.D., Els, T., Spreer, J., Herpers, M., Krause, T., Moser, E., and Lucking, C.H. (2003). Activation of a residual cortical network during painful stimulation in long-term postanoxic vegetative state: a $15 \mathrm{O}-\mathrm{H} 2 \mathrm{O}$ PET study. J Neurol Sci 212, 85-91.

Koppelstaetter, F., Siedentopf, C.M., Rhomberg, P., Lechner-Steinleitner, S., Eisner, W., and Golaszewski, S.M. (2007). FMRT vor Motorkortexstimulation bei Phantomschmerz: Ein Fallbericht. Nervenarzt.

Korvenoja, A., Huttunen, J., Salli, E., Pohjonen, H., Martinkauppi, S., Palva, J.M., Lauronen, L., Virtanen, J., Ilmoniemi, R.J., and Aronen, H.J. (1999). Activation of multiple cortical areas in response to somatosensory stimulation: combined magnetoencephalographic and functional magnetic resonance imaging. Hum Brain Mapp 8, 13-27.

Krause, T., Kurth, R., Ruben, J., Schwiemann, J., Villringer, K., Deuchert, M., Moosmann, M., Brandt, S., Wolf, K., Curio, G., and Villringer, A. (2001). Representational overlap of adjacent fingers in multiple areas of human primary somatosensory cortex depends on electrical stimulus intensity: an fMRI study. Brain Res 899, 36-46.

Kurth, R., Villringer, K., Curio, G., Wolf, K.J., Krause, T., Repenthin, J., Schwiemann, J., Deuchert, M., and Villringer, A. (2000). fMRI shows multiple somatotopic digit representations in human primary somatosensory cortex. Neuroreport 11, 1487-91.

Kurth, R., Villringer, K., Mackert, B.M., Schwiemann, J., Braun, J., Curio, G., Villringer, A., and Wolf, K.J. (1998). fMRI assessment of somatotopy in human Brodmann area 3b by electrical finger stimulation. Neuroreport 9, 207-12. 
Laureys, S., Faymonville, M.E., Peigneux, P., Damas, P., Lambermont, B., Del Fiore, G., Degueldre, C., Aerts, J., Luxen, A., Franck, G., Lamy, M., Moonen, G., and Maquet, P. (2002). Cortical processing of noxious somatosensory stimuli in the persistent vegetative state. Neuroimage 17, 732-41.

Lee, C.C., Jack, C.R. Jr, and Riederer, S.J. (1998). Mapping of the central sulcus with functional MR: active versus passive activation tasks. AJNR Am J Neuroradiol 19, 847-52.

Maldjian, J.A., Gottschalk, A., Patel, R.S., Detre, J.A., and Alsop, D.C. (1999a). The sensory somatotopic map of the human hand demonstrated at 4 Tesla. Neuroimage 10, 55-62.

Maldjian, J.A., Gottschalk, A., Patel, R.S., Pincus, D., Detre, J.A., and Alsop, D.C. (1999b). Mapping of secondary somatosensory cortex activation induced by vibrational stimulation: an fMRI study. Brain Res 824, 291-5.

Mazziotta, J.C.a.T.A.W. (2000). Brain Mapping: The methods. Academic Press).

Mima, T., Sadato, N., Yazawa, S., Hanakawa, T., Fukuyama, H., Yonekura, Y., and Shibasaki, H. (1999). Brain structures related to active and passive finger movements in man. Brain 122 ( Pt 10), 1989-97.

Moore, C.I., Stern, C.E., Corkin, S., Fischl, B., Gray, A.C., Rosen, B.R., and Dale, A.M. (2000). Segregation of somatosensory activation in the human rolandic cortex using fMRI. J Neurophysiol 84, 558-69.

Nelson, A.J., Staines, W.R., Graham, S.J., and McIlroy, W.E. (2004). Activation in SI and SII: the influence of vibrotactile amplitude during passive and task-relevant stimulation. Brain Res Cogn Brain Res 19, 174-84.

Ogawa, S., Lee, T.M., Kay, A.R., and Tank, D.W. (1990). Brain magnetic resonance imaging with contrast dependent on blood oxygenation. Proc Natl Acad Sci U S A 87, 9868-72.

Ogawa, S., Tank, D.W., Menon, R., Ellermann, J.M., Kim, S.G., Merkle, H., and Ugurbil, K. (1992). Intrinsic signal changes accompanying sensory stimulation: functional brain mapping with magnetic resonance imaging. Proc Natl Acad Sci U S A 89, 5951-5.

Penfield, W.a.B.E. (1937). Somatic motor and sensory representation in the cerebral cortex of man as studied by electrical stimulation. Brain 60, 389-443.

Peyron, R., Laurent, B., and Garcia-Larrea, L. (2000). Functional imaging of brain responses to pain. A review and meta-analysis (2000). Neurophysiol Clin 30, 263-88.

Piezomechanik Gmbh (ed). (2002). Piezoelectric bending actuators. http:/ / www.piezomechanik.com.

Piza, H. (2000). [Transplantation of hands in Innsbruck]. Wien Klin Wochenschr 112, 563-5.

Polonara, G., Fabri, M., Manzoni, T., and Salvolini, U. (1999). Localization of the first and second somatosensory areas in the human cerebral cortex with functional MR imaging. AJNR Am J Neuroradiol 20, 199-205.

Pons, T.P., Garraghty, P.E., and Mishkin, M. (1992). Serial and parallel processing of tactual information in somatosensory cortex of rhesus monkeys. J Neurophysiol 68, 518-27.

Rausch, M., Spengler, F., and Eysel, U.T. (1998). Proprioception acts as the main source of input in human S-I activation experiments: a functional MRI study. Neuroreport 9, 2865-8.

Recanzone, G.H., Merzenich, M.M., and Jenkins, W.M. (1992). Frequency discrimination training engaging a restricted skin surface results in an emergence of a cutaneous response zone in cortical area 3a. J Neurophysiol 67, 1057-70.

Riener, R., Villgrattner, T., Kleiser, R., Nef, T., and Kollias, S. (2005). fMRI compatible electromagnetic haptic device. Conf Proc IEEE Eng Med Soc 2005. Conf Proceedings 7024-7027. 
Roelcke, U., Curt, A., Otte, A., Missimer, J., Maguire, R.P., Dietz, V., and Leenders, K.L. (1997a). Influence of spinal cord injury on cerebral sensorimotor systems: a PET study. J Neurol Neurosurg Psychiatry 62, 61-5.

Roelcke, U., Curt, A., Otte, A., Missimer, J., Maguire, R.P., Dietz, V., and Leenders, K.L. (1997b). Influence of spinal cord injury on cerebral sensorimotor systems: a PET study. J Neurol Neurosurg Psychiatry 62, 61-5.

Ruben, J., Schwiemann, J., Deuchert, M., Meyer, R., Krause, T., Curio, G., Villringer, K., Kurth, R., and Villringer, A. (2001). Somatotopic organization of human secondary somatosensory cortex. Cereb Cortex 11, 463-73.

Seifert, F. and Maihofner, C. (2007). Representation of cold allodynia in the human brain--a functional MRI study. Neuroimage 35, 1168-80.

Seitz, R.J. and Roland, P.E. (1992). Vibratory stimulation increases and decreases the regional cerebral blood flow and oxidative metabolism: a positron emission tomography (PET) study. Acta Neurol Scand 86, 60-7.

Servos, P., Zacks, J., Rumelhart, D.E., and Glover, G.H. (1998). Somatotopy of the human arm using fMRI. Neuroreport 9, 605-9.

Sterr, A., Shen, S., Zaman, A., Roberts, N., and Szameitat, A. (2007). Activation of SI is modulated by attention: a random effects fMRI study using mechanical stimuli. Neuroreport 18, 607-11.

Stippich, C., Hofmann, R., Kapfer, D., Hempel, E., Heiland, S., Jansen, O., and Sartor, K. (1999a). Somatotopic mapping of the human primary somatosensory cortex by fully automated tactile stimulation using functional magnetic resonance imaging. Neurosci Lett 277, 25-8.

Stippich, C., Hofmann, R., Kapfer, D., Hempel, E., Heiland, S., Jansen, O., and Sartor, K. (1999b). Somatotopic mapping of the human primary somatosensory cortex by fully automated tactile stimulation using functional magnetic resonance imaging. Neurosci Lett 277, 25-8.

Takanashi, M., Abe, K., Yanagihara, T., Oshiro, Y., Watanabe, Y., Tanaka, H., Hirabuki, N., Nakamura, H., and Fujita, N. (2001). Effects of stimulus presentation rate on the activity of primary somatosensory cortex: a functional magnetic resonance imaging study in humans. Brain Res Bull 54, 125-9.

Tempel, L.W. and Perlmutter, J.S. (1990). Abnormal vibration-induced cerebral blood flow responses in idiopathic dystonia. Brain 113 ( Pt 3), 691-707.

Tempel, L.W. and Perlmutter, J.S. (1992). Vibration-induced regional cerebral blood flow responses in normal aging. J Cereb Blood Flow Metab 12, 554-61.

Tharin, S. and Golby, A. (2007). Functional brain mapping and its applications to neurosurgery. Neurosurgery 60, 185-201; discussion 201-2.

Toga, A. W. and Mazziotta, J. C. Brain Mapping. The Methods. Second Edition. Academic Press, San Diego, CA, 2002.

Wienbruch, C., Candia, V., Svensson, J., Kleiser, R., and Kollias, S.S. (2006). A portable and lowcost fMRI compatible pneumatic system for the investigation of the somatosensensory system in clinical and research environments. Neurosci Lett 398, 183-8.

Xu, X., Fukuyama, H., Yazawa, S., Mima, T., Hanakawa, T., Magata, Y., Kanda, M., Fujiwara, N., Shindo, K., Nagamine, T., and Shibasaki, H. (1997). Functional localization of pain perception in the human brain studied by PET. Neuroreport 8, 555-9. 


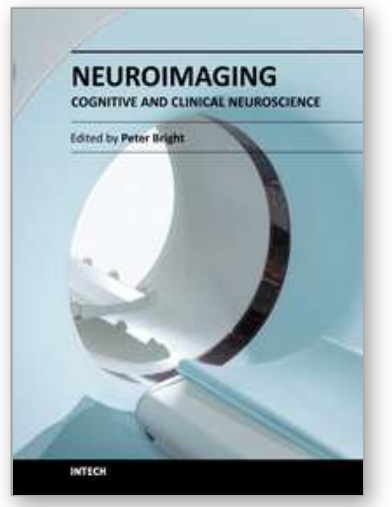

\author{
Neuroimaging - Cognitive and Clinical Neuroscience \\ Edited by Prof. Peter Bright
}

ISBN 978-953-51-0606-7

Hard cover, 462 pages

Publisher InTech

Published online 16, May, 2012

Published in print edition May, 2012

The rate of technological progress is encouraging increasingly sophisticated lines of enquiry in cognitive neuroscience and shows no sign of slowing down in the foreseeable future. Nevertheless, it is unlikely that even the strongest advocates of the cognitive neuroscience approach would maintain that advances in cognitive theory have kept in step with methods-based developments. There are several candidate reasons for the failure of neuroimaging studies to convincingly resolve many of the most important theoretical debates in the literature. For example, a significant proportion of published functional magnetic resonance imaging (fMRI) studies are not well grounded in cognitive theory, and this represents a step away from the traditional approach in experimental psychology of methodically and systematically building on (or chipping away at) existing theoretical models using tried and tested methods. Unless the experimental study design is set up within a clearly defined theoretical framework, any inferences that are drawn are unlikely to be accepted as anything other than speculative. A second, more fundamental issue is whether neuroimaging data alone can address how cognitive functions operate (far more interesting to the cognitive scientist than establishing the neuroanatomical coordinates of a given function - the where question).

\title{
How to reference
}

In order to correctly reference this scholarly work, feel free to copy and paste the following:

S.M. Golaszewski, M. Seidl, M. Christova, E. Gallasch, A.B. Kunz, R. Nardone, E. Trinka and F. Gerstenbrand (2012). Somatosensory Stimulation in Functional Neuroimaging: A Review, Neuroimaging - Cognitive and Clinical Neuroscience, Prof. Peter Bright (Ed.), ISBN: 978-953-51-0606-7, InTech, Available from: http://www.intechopen.com/books/neuroimaging-cognitive-and-clinical-neuroscience/somatosensorystimulation-in-functional-neuroimaging

\section{INTECH}

open science | open minds

\author{
InTech Europe \\ University Campus STeP Ri \\ Slavka Krautzeka 83/A \\ 51000 Rijeka, Croatia \\ Phone: +385 (51) 770447 \\ Fax: +385 (51) 686166 \\ www.intechopen.com
}

\author{
InTech China \\ Unit 405, Office Block, Hotel Equatorial Shanghai \\ No.65, Yan An Road (West), Shanghai, 200040, China \\ 中国上海市延安西路65号上海国际贵都大饭店办公楼405单元 \\ Phone: +86-21-62489820 \\ Fax: +86-21-62489821
}


(C) 2012 The Author(s). Licensee IntechOpen. This is an open access article distributed under the terms of the Creative Commons Attribution 3.0 License, which permits unrestricted use, distribution, and reproduction in any medium, provided the original work is properly cited. 